Research Article

\title{
Flexible Optimization of International Shipping Routes considering Carbon Emission Cost
}

\author{
Yao Yu $\mathbb{D}^{1},{ }^{1}$ Jincheng Tu, ${ }^{1}$ Kun Shi, ${ }^{1}$ Mei Liu, ${ }^{2}$ and Jihong Chen ${ }^{1}$ \\ ${ }^{1}$ College of Transport and Communications, Shanghai Maritime University, Shanghai 201306, China \\ ${ }^{2}$ China Institute of FTZ Supply Chain, Shanghai Maritime University, Shanghai 201306, China
}

Correspondence should be addressed to Yao Yu; yaoyu@shmtu.edu.cn

Received 16 December 2020; Revised 13 January 2021; Accepted 28 January 2021; Published 10 February 2021

Academic Editor: Aditya Rio Prabowo

Copyright (C) 2021 Yao Yu et al. This is an open access article distributed under the Creative Commons Attribution License, which permits unrestricted use, distribution, and reproduction in any medium, provided the original work is properly cited.

Carbon emissions cost is a potential effective measure to restrict hydrocarbon pollution in the international shipping trade. The minimization of the total cost is pursued by ship operators, whereas voyage cost is increasingly involving the replacement of clean fuel and changing the cost of the shipping route. A flexible optimization method focusing on maximizing the total profit is developed in terms of sailing speed optimization and single port skips integrate carbon emission influence. An actual ocean shipping route from Shanghai to Rotterdam is applied to validate the effectiveness of the proposed models. The results have shown that the shipping route profit is volatile along with the sailing speed and the number of port calls. However, the profit will be maximized when applying the single port skip and will slow down the sailing speed at the same time. The demand of planned skip port can be supported by a short line container. A system composed of ocean container liner and short line container can improve the profit by $4.05 \%$ and reduce the carbon emission by $19.70 \%$. Furthermore, sensitive results show that the profit is less affected by the changing of the carbon emission cost. A small size container has enough ability to solve the short transportation demand in adjacent ports and convert extraberthing cost into profit. These findings can provide reliable support for the shipping route decision process considering future carbon emission costs.

\section{Introduction}

Shipping plays an important role in international logistics, but while bringing huge economic benefits, it is also causing environmental pollutants. Ships consume a lot of fossil fuel and produce a great number of air pollutant emissions during transportation, which may cause a negative impact on the environment $[1,2]$. As a result of the rapid development of the shipping industry, the carbon emission from ship transportation has grown by an average of $0.3 \%$ every year, accounting for about $2.8 \%$ of the world [3]. Massive greenhouse gases are the main cause of global warming [4]. According to the greenhouse gas emission report of the Fourth International Maritime Organization (IMO), the carbon intensity of international maritime transportation decreased by about $11 \%$ from 2012 to 2018 , but the annual emission of greenhouse gas increased from 977 million tons to 1076 million tons. It is estimated that by 2050 , with the continuous growth of shipping demand, carbon dioxide emissions will increase by about 50\% compared with 2018 and $90-130 \%$ compared with 2008 . [5].

Moreover, charging carbon emission such as carbon tax policy is a future powerful emission-reduction policy that takes into account the cost of shipping. The so-called carbon tax is levied primarily on carbon emissions from fossil fuels. According to the "bottom-up" estimation method of ship emission, fossil fuels consumptions are directly proportional to ship emissions [6]. A lot of fuel consumption will produce more air pollutants. Based on the statistics of the 2018 Fuel Market Analysis Report, the total emissions demand of oil fuel in China was about 19.45 million tons, an increase of 1.7 million tons, or $9.85 \%$ year on year [7]. Therefore, imposing the extra carbon charing on the large amount of fuel consumed can achieve the goal of controlling fuel consumption by increasing operating costs, thereby mitigating pollutant emissions. Ship speeds also have important impacts on 
carbon emissions and transport costs. Lindstad et al. [8] pointed out that reducing the speed can effectively decrease the ship pollutant emissions. According to the data released by the OOCL shipping company, the port of Los Angeles heading for a voyage to Kaohsiung has a $6 \%$ drop in speed and a $30 \%$ drop in fuel costs. Since there exist positive correlations between carbon emissions and fuel consumption, speed reduction not only optimizes the amount of fuel consumption but also reduces carbon emissions. Therefore, potential carbon emission cost and the measure of the reduction of ship speed are equally important for the reduction of ship emissions.

In recent years, a large number of researches mainly focus on the optimization of the sailing speed, demandbased port selection, and planning without considering carbon emission. In the study of speed optimization, the influence of ship mechanical structure and external factors on ship speed reduction should be considered synthetically. Some researchers $[9,10]$ analyzed the main engine fuel consumption and route time changes at different speeds, and the results showed that fuel consumption accounted for about $20 \%-40 \%$ of the total navigation cost and constructed a functional relationship between fuel consumption and navigation speed, as shown in equation (1). Moreover, reducing the sailing speed of the ship can decrease running costs. Some researchers $[11,12]$ have studied the effect on the cost of ship transportation after the ship has slowed down. Studies pointed out that the cost of carbon emission decreases with the decrease in speed, but the transportation restriction cost increases gradually.

Considering the liner transportation and ship scheduling under emission control influence, Prpicorsic et al. [13] and Simonsen et al. [14] introduced ship carbon emission costs to plan low carbon transportation routes. De et al. [15] quantified the expression of carbon emission, and a mixedinteger linear model considering the demand of different linked ports is proposed to calculate the optimal speed. Dulebenets [16] evaluated whether vessel speed reduction can be a potentially cost-effective carbon mitigation option for ships calling on US ports. The results showed that the shipping profit closely depending on how the fleet responds to a speed reduction mandate. Corbett et al. [17] indicated that the carbon tax value might cause significant changes in the design of vessel schedules in referring to the environmental improvement issues, i.e., decreasing the vessel sailing speed to reduce fuel consumption and carbon dioxide emissions. Reducing speed and fuel consumption is equivalent to improving energy efficiency, but the increase in flight time leads to a decrease of industry profit $[18,19]$. Abioye et al. and Sheng et al. [20,21] considered ECA (Emission Control Area) policy to adjust the speed and route and increase the profit. In order to reduce the cost of carbon emissions, some researchers $[19,22]$ reconfigure the transportation network. These studies $[16,23,24]$ also analyzed the applicability of the liner subshipment and the selecting optimal route design considering carbon cost. It is shown that the proposed MNL mixed-integer linear model is suitable for the liner fleet deployment, but the flexible countermeasures brought by the model under the reduced speed navigation are not considered, such as the selection of the link ports and then plan to skip.

In summary, the current research mainly focuses on the effect of ship speed and ship route planning on emission reduction. There are few kinds of research on flexible route planning, such as skipping port combined with carbon emission cost aiming to increase shipping profit. Therefore, this study proposes an optimization method for the integration of speed design and flexible port selection. Taking the profit maximization of transport ships as the goal, the numerical verification and sensitivity analysis are carried out considering the cost of the carbon emission.

\section{Analysis of Influencing Factors}

2.1. Impact of Liner Speed on Cost and Route. Voyage speed has an important impact on the liner cycle and transport costs. The relationship between fuel consumption and speed can be expressed in the following equation:

$$
Q=k * v^{n}
$$

where $Q$ is the daily fuel consumption of the ship (unit: per ton/day); $k$ presents the ship function coefficient, which is related to the ship's condition, deadweight, and the navigation environment; $v$ is the ship speed (unit: knot). Åström et al. [19] indicate that in ocean-going container liner transportation, the value of $n$ is 3. Fagerholt et al. [28] show that the fuel consumption per time unit increases to a power of three with speed. In addition, Bialystocki et al. [11] also point out that the relationship among voyage $L$ (unit: nautical miles), time $t$ (unit: hour), and speed $v$ (unit: knot), as shown in the following equation:

$$
t=\frac{L}{v}
$$

According to equations (1) and (2), the vessel's fuel consumption per nautical mile per hour is $Q_{\text {dis }}$ and the expression formula is shown below:

$$
Q_{\mathrm{dis}}=\frac{k * v^{2}}{24} \text {. }
$$

In general, the sailing route can be adjusted according to the capacity when speed decreases. However, if we take port arrival time windows into account, there are two ways to solve the negative effects caused by the decrease in speed. First of all, we can increase the number of shipping routes, i.e., reduce the liner shipping interval. The second option is to selectively reject some relatively small port calls. In addition, liner at a lower speed can often increase the probability of punctuality to the port; i.e., when liner encountered unexpected circumstances, a port time extension can be increased to compensate for the loss of time. The quantization of flexibility is also related to the speed reduction ratio.

2.2. Impact of Carbon Emission Costs on Liner Route Optimization. The carbon emission cost levied on fossil fuel based on their carbon content or carbon emission, thus 
achieving the purpose of controlling carbon emissions from shipping by means of increasing the cost of shipping. Currently, the United States, Australia, Japan, and other economically developed countries and regions such as the European Union have issued relevant carbon emission policies. The carbon emission cost model is shown as follows:

$$
C=Q_{c o_{2}} \times D
$$

where $C$ represents the carbon emission cost (unit: USD); $Q_{\mathrm{CO}_{2}}$ is the carbon emission (unit ton); D is the carbon emission cost rate (unit: USD/ton). For the determination of carbon emissions, De et al. [15] propose that the composition of carbon emissions is equal to the product of fuel consumption and carbon emission factors based on existing research. Among them, the carbon emission factor is a measure of the ability of fuel consumption to convert to carbon dioxide, and the carbon emission factor under heavy oil is picked as 3.021 [16], that is,

$$
Q_{c o_{2}}=Q_{o} \times 3.021
$$

where $Q_{o}$ represent the fuel consumption (unit: tons). According to equation (3), the cost of carbon emissions can be summarized as follows:

$$
C=D * 3.021 * \operatorname{dis}_{i j} * \frac{k * v^{2}}{24},
$$

where $\operatorname{dis}_{i j}$ is the distance between port $i$ and port $j$ (unit nautical mile);

The promulgation of potential carbon emission policies has a great impact on the total profits of liner routes. Apart from the improvement of the ship's own power structure, due to the easy payment of more carbon emission cost under high-speed navigation, some liners will choose to reduce the speed to achieve the purpose of reducing the cost of the voyage. However, speed reduction will lead to the change of the departure schedule, and the route must be reallocated or increase the number of ships and other means.

\section{Construction of Flexible Optimization Model}

3.1. Assumptions. In this study, considering the optimization of liner speed and the redistribution of linked ports, the following assumptions are made for the proposed flexible optimization model:

(1) Port cargo demand, interport distance, and freight between ports are known under voyage trip.

(2) Port fees are known; the speed of loading and unloading is identical through the whole shipping.

(3) The times of pilotage are the same and known when the ship calls at each port.

(4) The weather conditions and shipping route circumstances in each section are the same.

(5) Only consider using heavy oil. Its voyage cost and carbon emission cost rate are known and do not vary with the ship's sailing time.
(6) With the original departure port and the port at the farthest part of the route as the terminal ports, the ship may not choose to call at any port except the terminal port.

The voyage costs mainly include fuel charges, potential carbon emission cost charges, port charges, loading and unloading charges, berthing charges for ships in the course of loading and unloading, and penalty charges in case of the port skip. To ensure the on-time arrival of the ship in the next cycle when the ship is sailing at a slower speed, only the method of port skipping can be adopted, and the losses caused by the port dumping are also included in the cost.

Ship company cost in the proposed model includes fuel cost, carbon emission cost, port operation fee, container handling cost, ship berthing cost, and port skip penalty cost. The revenue of ship transportation mainly comes from freight; we take the product of freight between loading and unloading as the revenue of ship transportation.

In this study, we sum the cost of all sections of a certain route as the total cost of the route, and the sum of the revenue of all sections as the total revenue of the route. A mixed nonlinear programming model with the maximum difference between total revenue and cost as the objective function is established. Table 1 declares the variables for the model.

3.2. Modeling. According to the above assumptions and conditions, the total profit objective function of the route can be represented as follows:

$$
\begin{aligned}
\max : P= & \sum \sum\left[u_{i j} * \operatorname{vol}_{i j} *\left(f_{i j}-2 * f z\right)\right]-\sum \sum \\
& .\left\{X_{i j} *\left[(E+3.17 * D) * \operatorname{dis}_{i j} * \frac{k * v^{2}}{24}+T\right]\right\}, \\
& -\sum \sum\left[\left(1-u_{i j}\right) * \theta * d e_{i j} * f_{i j}\right] \\
& -\left(\frac{2 * \sum \sum u_{i j} * \operatorname{vol}_{i j}}{v z}\right) * \frac{f s}{24}
\end{aligned}
$$

where $\sum \sum\left[u_{i j} * \operatorname{vol}_{i j} *\left(f_{i j}-2 * f z\right)\right]$ is the total freight revenue for removal of loading and unloading charges; $\sum \sum\left\{X_{i j} *\left[(E+3.17 * D) * \operatorname{dis}_{i j} *\left(k * v^{2} / 24\right)+T\right]\right\}$ refers to the cost of fuel, carbon emission cost, and port fees during transportation; $\sum \sum\left[\left(1-u_{i j}\right) * \theta * d e_{i j} * f_{i j}\right]$ is the penalty for port skip; and $\left(2 * \sum \sum u_{i j} * \operatorname{vol}_{i j} / v z\right) * f s / 24$ is the ship berthing cost in port.

The decision variables are constrained as shown in the following equation:

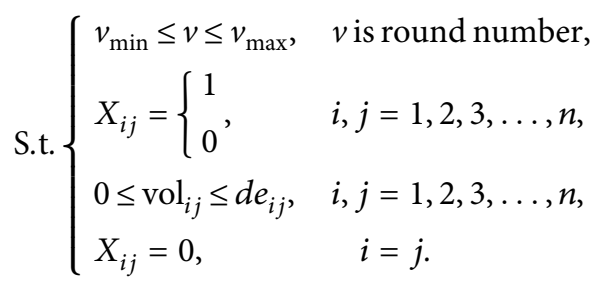


TABLE 1: Variable declaration.

\begin{tabular}{lc}
\hline Symbol & Symbol meaning \\
\hline$P$ & Total profit on routes excluding operating and capital costs (USD) \\
$E$ & Number of ports in routes \\
$i, j$ & Fuel price $(\$ /$ ton) \\
$\operatorname{dis}_{i j}$ & Port $i$ and port $j$ \\
$v$ & The distance from port $i$ to port $j$ (nautical mile) \\
$u_{i j}$ & The speed at which ships sail on the course (knot) \\
$X_{i j}$ & Whether there is a container transport between port $i$ and port $j$ \\
$k$ & Whether there is an actual route between ports $i$ and $j$ \\
$T$ & Ship functional coefficient \\
$f z$ & Port surcharge such as terminal charge \\
$\theta$ & Standard container handling charges (USD/TEU) \\
vol $l_{i j}$ & Penalty coefficient for port skip, between 0 and 1 \\
$d e_{i j}$ & Container volume from port $i$ to port $j$ \\
$f_{i j}$ & Actual demand for container transport between port $i$ to port $j$ \\
$D$ & Standard container unit freight at port $i$ to port $j$ (USD/TEU) \\
$t y$ & Carbon emission cost (USD/TEU) \\
$v z$ & Container handling speed (TEU/h) \\
$f s$ & The cost of a ship at anchor (USD/TEU) \\
$t w$ & The maximum totage time of container ships in ports and other time consumption other that the shipping company specifies at which the ship will travel on that route (hour) \\
cap & Maximum liner load \\
$f u_{i}$ & Auxiliary coefficient
\end{tabular}

The intermediate variable constraint is shown in the following equation:

$$
\text { S.t. } u_{i j}=\left\{\begin{array}{ll}
\sum_{j=i}^{n} x_{i j} * \sum_{i=1}^{j} x_{i j} & 0<j<i \leq n, \\
\sum_{j=1}^{i} x_{i j} * \sum_{i=j}^{n} x_{i j} & 0<i<j \leq n,
\end{array} \quad i, j\right. \text { are round numbers. }
$$

The time constraints are shown in the following equation:

$$
\text { S.t. } \frac{\sum \sum X_{i j} * \operatorname{dis}_{i j}}{v}+\frac{2 * \sum \sum u_{i j} * \operatorname{vol}_{i j}}{v z}+\sum \sum X_{i j} * t y<t w .
$$

The onward route capacity constraints are shown in the following equation:

$$
\text { S.t. }\left\{\begin{array}{l}
\sum_{i=1}^{1} \sum_{j=2}^{n}\left(u_{i j} * \operatorname{vol}_{i j}\right) \leq \mathrm{cap}, \\
\sum_{i=1}^{2} \sum_{j=3}^{n}\left(u_{i j} * \operatorname{vol}_{i j}\right) \leq \mathrm{cap}, \\
\sum_{i=1}^{n-1} \sum_{j=n}^{n}\left(u_{i j} * \operatorname{vol}_{i j}\right) \leq \mathrm{cap} .
\end{array}\right.
$$

The return route capacity constraints are shown in the following equation:

$$
\text { S.t. }\left\{\begin{array}{l}
\sum_{i=n}^{n} \sum_{j=1}^{n-1}\left(u_{i j} * \operatorname{vol}_{i j}\right) \leq \mathrm{cap}, \\
\sum_{i=n-1}^{n} \sum_{j=1}^{n-2}\left(u_{i j} * \operatorname{vol}_{i j}\right) \leq \mathrm{cap}, \\
\sum_{i=n-3}^{n} \sum_{j=1}^{n-3}\left(u_{i j} * \operatorname{vol}_{i j}\right) \leq \mathrm{cap} \\
\sum_{i=2}^{n} \sum_{j=1}^{1}\left(u_{i j} * \operatorname{vol}_{i j}\right) \leq \mathrm{cap}, \quad n>3
\end{array}\right.
$$

The capacity constraints can be presented in Figure 1. When the ship starts from port 1, the load can be recorded as vol $_{12}$ (Containers between 1 and 2 ports) and the sum of containers of $\mathrm{vol}_{13}$ and $\mathrm{vol}_{14}$. When the ship arrives at port 2, unload the corresponding container $\mathrm{vol}_{12}$ and load the container of $\operatorname{vol}_{23}$ and $\operatorname{vol}_{24}$.

Route constraints are as follows:

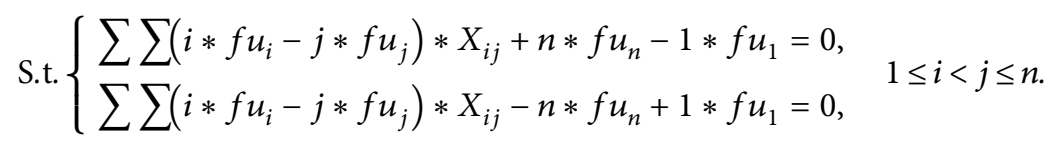




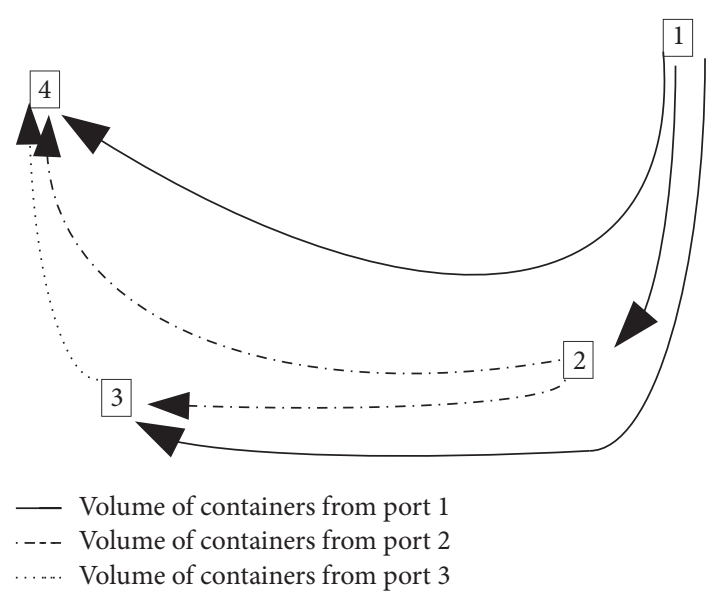

FIgURE 1: Schematic diagram of capacity constraints.

Each segment of the journey and return is regarded as a vector, and the characteristics of each other can be eliminated by adding the first and last parts of the vector. Therefore the segment of the journey and return is always composed of routes, thus ensuring the effectiveness of the routes.

\section{Example Analysis}

4.1. Description of Parameters. To evaluate the applicability of the proposed models and the efficiency of the port skip strategy, we adopt a real trading route case from Asia to Europe provided by OOCL. This route involved eight ports as shown in Figure 2. There is the ship operated on the route derived from eight ports: Shanghai, Ningbo, Yantian, Singapore, Dubai, Antwerp, Rotterdam, and Hamburg. We use the proposed models to select the optimal voyages between two ports and optimal route profit on the whole route design. We assume the ship firstly departs from Shanghai and finally back to Shanghai. The distance among individual ports is shown in Table 2 .

We regard port as the original set of $n$ elements, while (port, port) as its derived set includes variables of shipping route segment and variables of cargo transport demand. The actual container liner parameters are shown in Table 3.

The value range of the ship function coefficient $k$ can be calculated by linear regression according to historic fuel cost and average speed. Here, let $k=0.0112$ at 8000 TEU situation. Port fees and miscellaneous port charges, berthing charges, and handling charges are valued at $\$ 21,000, \$ 2,500$ per hour, and $\$ 150 / \mathrm{TEU}$, respectively, according to China Port Association [25]. Pilotage time and stay in the port (excluding loading and unloading time) is 4 hours. Select the Shanghai Port-Hamburg Port route; the route related parameters are shown in Table 4.

4.2. Analysis of Results. The original section is Shanghai Port-Ningbo Port-Yantian Port-Singapore Port-Dubai PortAntwerp Port-Rotterdam Port-Hamburg Port. The existence of the optimized segment is shown in Table 5.
As presented in Table 5, the optimized result is obtained by using LINGO 16.0. The optimized route is Shanghai Port-Ningbo Port-Yantian Port-Singapore Port-Antwerp Port-Rotterdam Port-Hamburg Port. The return route is Hamburg-Rotterdam-Antwerp-Dubai-Singapore-YantianNingbo-Shanghai. Compared to the original route, the port of Dubai is not on the visiting list. The container transport optimization results are shown in Table 6 .

The comparisons of original and optimized routes results are shown in Table 7.

As presented in Table 7, the profit-making performance of the optimized route is significantly higher than that of the original route. The speed of the voyage decreased by $13.70 \%$. The total freight volume decreased by $7.8 \%$, and the total sailing distance decreased by $10.8 \%$. The voyage profit increased by $3.70 \%$. The voyage time was about equal to the original route time (only 7 hours). The total fuel consumption decreased by $33.48 \%$. The carbon emission cost decreased by about $33.47 \%$.

According to the analysis of cost structure, the proportion of carbon emission cost decreased from $5.75 \%$ to $3.69 \%$, and the proportion of fuel cost decreased from $30.23 \%$ to $19.40 \%$ under the simultaneous action of shipping at the same time.

\section{Sensitivity Analysis}

5.1. Impact of Changes in Carbon Emission Cost Rates on Voyage Profits. In this study, carbon emission cost is taken as an external uncertain factor that has an influence on the final profit of shipping companies. We assume all factors except carbon emission cost are not changing as the environmental variance and give a sensitivity analysis to test the performance of the total profit considering the carbon emission cost rate $D$, as written in the following equation:

$$
d P=-3.021 * \operatorname{dis}_{a} * \frac{k * v^{2}}{24} * d D,
$$

where dis $_{a}$ represents the total nautical mileage of the planning route.

From equation (14) and the optimized data calculation in the model example, it can be calculated as follows:

$$
d P=-12027 * d D \text {. }
$$

Equation (15) implies that when the carbon emission cost changes in $\$ 1$ per ton, the total profit of the route would reduce by $\$ 12,027$. The sensitive results of shipping profit with the changing rate of carbon emission cost are shown in Figure 3.

Though the carbon emission cost has been regarded as a additional potential sailing cost, the actual impact on the shipping profit is relatively small $(+1.23 \% \sim-2.16 \%)$. For example, when the carbon emission cost increases by $\$ 5$, the profit shrinks by about $0.6 \%$.

5.2. Impact of Port Skip on Port Transport. Since one or more ports would be skipped aiming to maintain maximum profit of ship carriers, substitute vessels should be considered to 


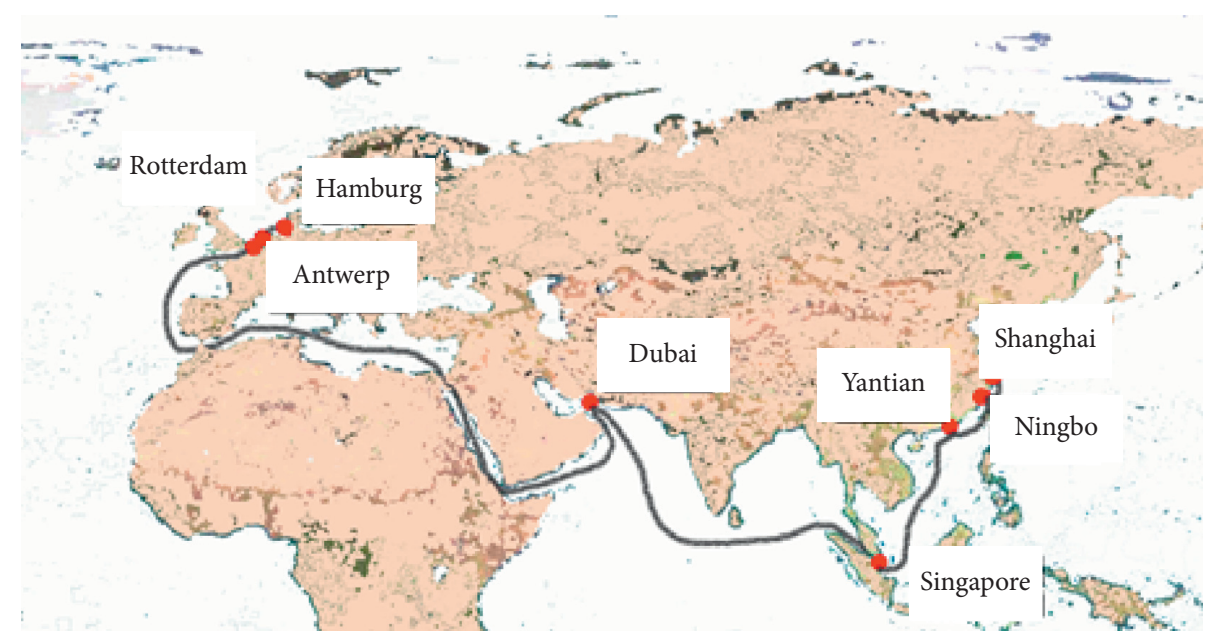

FIgURE 2: The shipping routes of eight ports.

TABle 2: The distance among individual ports ( $\mathrm{n}$ miles).

\begin{tabular}{lcccccccc}
\hline Dis $_{(\mathrm{i}, \mathrm{j})}$ & Shanghai & Ningbo & Yantian & Singapore & Dubai & Antwerp & Rotterdam & Hamburg \\
\hline Shanghai & 0 & 109 & 796 & 2148 & 5606 & 10431 & 10449 \\
Ningbo & 109 & 0 & 739 & 2090 & 5549 & 10373 & 10392 \\
Yantian & 796 & 739 & 0 & 1454 & 4911 & 9736 & 9754 \\
Singapore & 2148 & 2090 & 1454 & 0 & 3454 & 8279 & 8297 \\
Dubai & 5606 & 5549 & 4911 & 3454 & 0 & 6189 & 6207 & 10640 \\
Antwerp & 10431 & 10373 & 9736 & 8279 & 6189 & 0 & 2000 \\
Rotterdam & 10449 & 10392 & 9754 & 8297 & 6207 & 200 & 0 & 710 \\
Hamburg & 10740 & 10640 & 10002 & 8545 & 6455 & 710 & 480 & 480 \\
\hline
\end{tabular}

TABLE 3: Ship parameters.

\begin{tabular}{lc}
\hline Ship parameters & Numerical value \\
\hline The maximum deadweight of the ship (TEU) & 8000 \\
Minimum speed (knot) & 14 \\
Maximum speed (knot) & 27 \\
Container handling speed (Containers/h) & 120 \\
Ship function coefficient $k$ & 0.0112 \\
Port fees, etc. (USD) & 21000 \\
Parking charges (USD/day) & 2500 \\
Carbon emission factors & 3.021 \\
Pilotage time and stay in the port except for handling time (h) & 4 \\
Container handling charges (USD/TEU) & 150 \\
\hline
\end{tabular}

handle the transportation demand of the planned skipped port or cargo owner. For example, the transportation demand of Dubai port cargo (includes loading and unloading) is 1375 TEU. The number of untransported containers is totally $3440 \mathrm{TEU}$ according to the statistics of other calling ports. A 1436 TEU alternative container ship is chosen based on the remaining transportation demand of Dubai port. The substitute container ship is designed to accomplish the loading/unloading tasks in Dubai port. The 1436 TEU substitute ship information is as Table 8 shown.

As seen from equation (3), the $Q_{\text {dis }}$ per nautical mile consumption of the ship can be expressed as follows:
TABLE 4: Route parameters.

\begin{tabular}{lc}
\hline Route parameters & Numerical value \\
\hline Total voyage time (hours) & 1510 \\
Port penalty factor & 0.5 \\
Heavy oil price (RMB/ton) & 500 \\
Carbon emission cost rate (USD/ton) & 30 \\
\hline & \\
$\qquad Q_{\text {dis }}=\frac{0.0137 * v^{1.89}}{24} *$ dis.
\end{tabular}

The simulation results are shown in Table 9. 
TABLE 5: Results of segment optimization.

\begin{tabular}{lcccccccc}
\hline O/D & $\begin{array}{c}\text { Shanghai } \\
\text { port }\end{array}$ & $\begin{array}{c}\text { Ningbo } \\
\text { port }\end{array}$ & $\begin{array}{c}\text { Yantian } \\
\text { port }\end{array}$ & $\begin{array}{c}\text { Singapore } \\
\text { port }\end{array}$ & $\begin{array}{c}\text { Dubai } \\
\text { port }\end{array}$ & $\begin{array}{c}\text { Port } \\
\text { Antwerp }\end{array}$ & $\begin{array}{c}\text { Rotterdam } \\
\text { port }\end{array}$ & $\begin{array}{c}\text { Port } \\
\text { Hamburg }\end{array}$ \\
\hline Shanghai port & 0 & 1 & 0 & 0 & 0 & 0 & 0 & 0 \\
Ningbo port & 1 & 0 & 1 & 0 & 0 & 0 & 0 & 0 \\
Yantian port & 0 & 1 & 0 & 1 & 0 & 0 & 0 & 0 \\
Singapore port & 0 & 0 & 1 & 0 & 0 & 1 & 0 & 0 \\
Dubai port & 0 & 0 & 0 & 0 & 0 & 0 & 0 & 0 \\
Port Antwerp & 0 & 0 & 0 & 1 & 0 & 0 & 0 & 1 \\
Rotterdam & 0 & 0 & 0 & 0 & 0 & 1 & 0 & 0 \\
port & 0 & 0 & 0 & 0 & 0 & 0 & 1 \\
Port Hamburg & 0 & & 0 & 0 & & 0 \\
\hline
\end{tabular}

TABle 6: Cargo transport optimization.

\begin{tabular}{|c|c|c|c|c|c|c|c|c|}
\hline $\mathrm{O} / \mathrm{D}$ & $\begin{array}{c}\text { Shanghai } \\
\text { port }\end{array}$ & $\begin{array}{c}\text { Ningbo } \\
\text { port }\end{array}$ & $\begin{array}{c}\text { Yantian } \\
\text { port }\end{array}$ & $\begin{array}{c}\text { Singapore } \\
\text { port }\end{array}$ & $\begin{array}{c}\text { Dubai } \\
\text { port }\end{array}$ & $\begin{array}{c}\text { Port } \\
\text { Antwerp }\end{array}$ & $\begin{array}{l}\text { Rotterdam } \\
\text { port }\end{array}$ & $\begin{array}{c}\text { Port } \\
\text { Hamburg }\end{array}$ \\
\hline Shanghai port & 0 & 120 & 175 & 970 & 0 & 151 & 285 & 173 \\
\hline Ningbo port & 115 & 0 & 80 & 960 & 0 & 110 & 140 & 112 \\
\hline Yantian port & 240 & 180 & 0 & 870 & 0 & 125 & 165 & 137 \\
\hline Singapore port & 810 & 650 & 0 & 0 & 0 & 152 & 273 & 178 \\
\hline Dubai port & 0 & 0 & 0 & 0 & 0 & 0 & 0 & 0 \\
\hline Port Antwerp & 720 & 590 & 640 & 300 & 0 & 0 & 80 & 360 \\
\hline $\begin{array}{l}\text { Rotterdam } \\
\text { port }\end{array}$ & 980 & 710 & 860 & 580 & 0 & 90 & 0 & 150 \\
\hline Port Hamburg & 740 & 590 & 710 & 580 & 0 & 230 & 110 & 0 \\
\hline
\end{tabular}

TABLE 7: Comparison of original and optimized route data.

\begin{tabular}{lcc}
\hline Parameter & Original route & Optimization of rear routes \\
\hline Voyage profit (USD) & 9431979 & 9780768 \\
Speed of a ship (knot) & 22 & 19 \\
Time of voyage (h) & 1496 & 1503 \\
Total shipments (TEU) & 17566 & 16191 \\
Total sailing distance (nautical mile) & 25250 & 22522 \\
Total fuel consumption (ton) & 5703 & 3794 \\
Carbon emission cost (USD) & 542355 & 360809 \\
Number of linked ports & 8 & 7 \\
Profitability (USD/h) & 6305 & 6507 \\
\hline
\end{tabular}

$$
P=R-C_{V}-C o-C c .
$$

where $P$ represents the voyage net profit; $R$ donates the voyage revenue; $C_{V}$ is the voyage cost; $C o$ reflects the operating cost; $C$ Cmeans the capital cost.

This study assumes that the 1456 TEU container ship cooperates with 8000 TEU formulated as a group and the 1456 short line container considering the economical speed with reference to the cost efficiency. For example, we set the short line container speed as $13 \mathrm{kn}$. The chartering fee of a 1436 TEU container ship includes the following: daily capital cost is $\$ 8,700$; annual operating cost is $\$ 1480,000$, and average daily consumption of light crude oil is 2 tons (here we assume the consumption of the light crude oil is fixed while at berthing). According to inquire the price on China Maritime Services Network in April 2019, the light crude oil price was $\$ 650$ per ton. So we can calculate the voyage crude

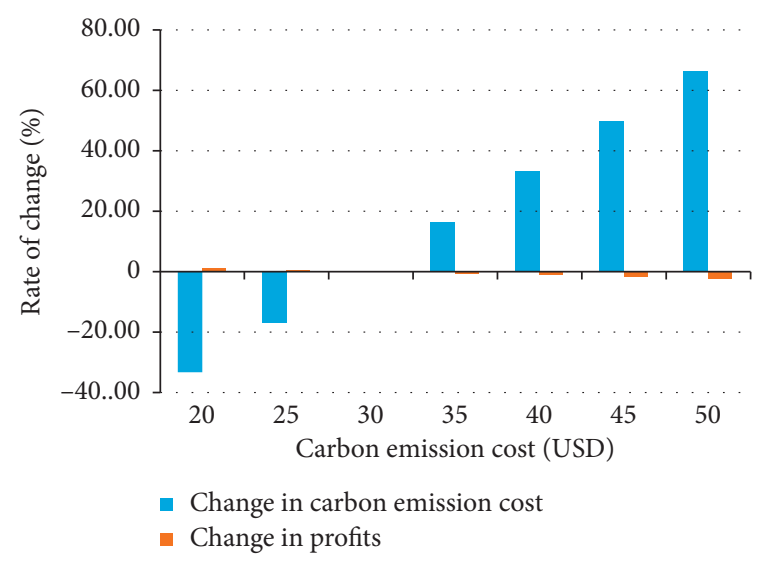

FIgURE 3: Chart of changes in shipping route profits with the carbon emission cost. 
TABLE 8: 1436 TEU container ship parameters.

\begin{tabular}{lr}
\hline Ship parameters & Numerical value \\
\hline The maximum deadweight of the ship (TEU) & 1436 \\
Service speed (knot) & 18.5 \\
Container handling speed (containers/hour) & 120 \\
Ship function coefficient $k$ & 0.0137 \\
Port fees, etc. (USD) & 21000 \\
Parking charges (USD/d) & 2500 \\
Carbon emission factors & 3.021 \\
Pilotage time and stay in the port except for handling time (h) & 4 \\
Container handling charges (USD/TEU) & 150 \\
Heavy oil prices (USD/ton) & 500 \\
Carbon emission cost rate (USD/ton) & 30 \\
\hline
\end{tabular}

TABLE 9: 1436 TEU ship route simulation results.

\begin{tabular}{lc}
\hline Model results parameters & Numerical value \\
\hline Voyage profit (USD) & 936839 \\
Speed of the ship (knot) & 13 \\
Total shipments (TEU) & 4815 \\
Total sailing distance (nautical miles) & 11325 \\
Travel time (hours) & 871 \\
Total fuel consumption (ton) & 824 \\
Number of linked ports & 8 \\
Profitability (USD/hour) & 622 \\
\hline
\end{tabular}

oil cost as $\$ 76,646$. Moreover, we calculated the emission cost of 1456 TEU is $\$ 74,675$. Based on the above, the profit from Shanghai-Hamburg is $\$ 108,191$ excluding emission cost, and the final profit is $\$ 33,516$ after carbon emission cost deduction. Therefore, the proposed scheme is feasible with respect to the positive profit result of an additional 1436 TEU container ship, which could be accepted by a shipping company.

In addition, it is worth noting that the simulation result implies that the smaller container ship has enough ability to solve the short transportation demand between adjacent ports and convert extra berthing cost into profit compare to a larger size of a container ship. Considering the profitability in terms of the voyage, a regional or branch container ship only costs $\$ 622$ per hour compared to $\$ 6,507$ an hour for 8,000 TEU ships even after route optimization. To sum up, the integration of ocean containers and short line supplement containers will have a significant improvement in the profit of the international shipping route.

\section{Conclusions}

This study analyzes marine transportation profit maximization issues considering carbon emission costs based on the actual freight demand in the international shipping trade. A flexible route optimization method is proposed to improve the shipping profit and decrease the carbon emission costs based on scheduled voyage cycles. An actual case, including routes from Asia to Europe, is applied to validate the effectiveness of the proposed model considering sailing speed optimization and port skip strategies. Only considering the ocean ship, the results show that the flexible optimization model can increase the voyage profit by $3.7 \%$ and reduce the carbon emission cost by $33.47 \%$. In the case of international shipping from Shanghai to Hamburg, the voyage distance has decreased by $10.8 \%$ and a $13.7 \%$ decline in sailing speed in this transportation. To compensate for the loss for the skipped port, a shortline container can be arranged to solve the demand of the one that is not calling.

It is worth noting that the final voyage profit is increased by $4.05 \%$ and the carbon emission cost is reduced by $19.70 \%$, which is better than that of the ocean container liner before optimization in the proposed whole system composed of two types of container ships. Finally, sensitivity analyses are performed to illustrate the impact of the different carbon emission cost rates on the voyage profit, revealing that the total profit would decrease/increase by $0.62 \%$ with a tiny increase/decrease by $\$ 5$ per ton of carbon emission cost enrollment.

However, the proposed method has some limitations including the timeliness of shortline containers and the external marine environment which need to be further discussed in the model. Therefore, the future research may focus on the following extensions: (1) integrated time windows to satisfy the on-time demand for each port; (2) consider the carbon emission regulations when vessel passing through ECA (Emission Control Areas); (3) adjust the port charge and port handling efficiency as dynamic parameters in the model; (4) conduct a multilevel analysis of internal factors (i.e., vessels mechanical conditions, manipulate response, etc.) and external factors (i.e., whether environmental or socioeconomic) to obtain the potential influence on voyage state with respect to the accordingly indirect emission control strategies, which have a significant impact on the final profit for shipping liner owners.

\section{Data Availability}

The data used to support the findings of this study are included within the article.

\section{Disclosure}

The authors are solely responsible for all the views and analyses in this paper.

\section{Conflicts of Interest}

The authors declare no conflicts of interest in their research. 


\section{Acknowledgments}

This study was supported by the "National Natural Science Foundation of China" (grant nos. 61603247 and 51879156) and high-level talent project funding plan of the transportation industry supported by the Ministry of Transport of the People's Republic of China (Grant No. 2019-012).

\section{References}

[1] J. J. Corbett, P. S. Fischbeck, and S. N. Pandis, "Global nitrogen and sulfur inventories for oceangoing ships," Journal of Geophysical Research: Atmospheres, vol. 104, no. D3, pp. 3457-3470, 1999.

[2] J.-P. Jalkanen, L. Johansson, J. Kukkonen, A. Brink, J. Kalli, and T. Stipa, "Extension of an assessment model of ship traffic exhaust emissions for particulate matter and carbon monoxide," Atmospheric Chemistry and Physics, vol. 12, no. 5, pp. 2641-2659, 2012.

[3] T. W. P. Smith, J. P. Jalkanen, B. A. Anderson et al., Third IMO Greenhouse Gas Study 2014, International Maritime Organization, London, UK, 2015.

[4] J. Chen, Y. Fei, and Z. Wan, "The relationship between the development of global maritime fleets and GHG emission from shipping," Journal of Environmental Management, vol. 242, pp. 31-39, 2019.

[5] J. Faber, S. Hanayama, S. Zhang et al., Fourth IMO Greenhouse Gas Study, International Maritime Organization, London, UK, 2020.

[6] U. Kesgin and N. Vardar, "A study on exhaust gas emissions from ships in Turkish Straits," Atmospheric Environment, vol. 35, no. 10, pp. 1863-1870, 2001.

[7] Shandong Provincial People's Government, Analysis Report of Fuel Oil Market in 2018, https://wenku.baidu.com/view/ 11c2b1f45cf7ba0d4a7302768e9951e79b89693d.html, 2018.

[8] H. Lindstad, B. E. Asbjørnslett, and A. H. Strømman, "Reductions in greenhouse gas emissions and cost by shipping at lower speeds," Energy Policy, vol. 39, no. 6, pp. 3456-3464, 2011.

[9] B. Yu, Z. Peng, Z. Tian, and B. Yao, "Sailing speed optimization for tramp ships with fuzzy time window," Flexible Services and Manufacturing Journal, vol. 31, no. 2, pp. 308330, 2019.

[10] S. Wang and X. Wang, "A polynomial-time algorithm for sailing speed optimization with containership resource sharing," Transportation Research Part B: Methodological, vol. 93, pp. 394-405, 2016.

[11] N. Bialystocki and D. Konovessis, "On the estimation of ship's fuel consumption and speed curve: a statistical approach," Journal of Ocean Engineering and Science, vol. 1, no. 2, pp. 157-166, 2016.

[12] K. Fagerholt, G. Laporte, and I. Norstad, "Reducing fuel emissions by optimizing speed on shipping routes," Journal of the Operational Research Society, vol. 61, no. 3, pp. 523-529, 2010.

[13] J. Prpicorsic, R. Vettor, O. M. Faltinsen, and C. G. Soares, "The influence of route choice and operating conditions on fuel consumption and CO2 emission of ships," Journal of Marine Science and Technology, vol. 21, no. 3, pp. 434-457, 2016.

[14] M. Simonsen, H. J. Walnum, and S. Gossling, "Model for estimation of fuel consumption of cruise ships," Energies, vol. 11, no. 5, p. 1059, 2018.

[15] A. De, V. K. R. Mamanduru, A. Gunasekaran, N. Subramanian, and M. K. Tiwari, "Composite particle algorithm for sustainable integrated dynamic ship routing and scheduling optimization," Computers \& Industrial Engineering, vol. 96, pp. 201-215, 2016.

[16] M. A. Dulebenets, "Green vessel scheduling in liner shipping: modeling carbon dioxide emission costs in sea and at ports of call," International Journal of Transportation Science and Technology, vol. 7, no. 1, pp. 26-44, 2018.

[17] J. J. Corbett, H. Wang, and J. J. Winebrake, "The effectiveness and costs of speed reductions on emissions from international shipping," Transportation Research Part D: Transport and Environment, vol. 14, no. 8, pp. 593-598, 2009.

[18] V. Kosmas and M. Acciaro, "Bunker levy schemes for greenhouse gas (GHG) emission reduction in international shipping," Transportation Research Part D: Transport and Environment, vol. 57, pp. 195-206, 2017.

[19] S. Åström, K. Yaramenka, H. Winnes, E. Fridell, and M. Holland, "The costs and benefits of a nitrogen emission control area in the Baltic and North Seas," Transportation Research Part D: Transport and Environment, vol. 59, pp. 223-236, 2018.

[20] O. F. Abioye, M. A. Dulebenets, J. Pasha, and M. Kavoosi, "A vessel schedule recovery problem at the liner shipping route with Emission Control Areas," Energies, vol. 12, no. 12, pp. 1-28, 2019.

[21] D. Sheng, Q. Meng, and Z. Li, "Optimal vessel speed and fleet size for industrial shipping services under the emission control area regulation," Transportation Research Part C: Emerging Technologies, vol. 105, pp. 37-53, 2019.

[22] W. L. Dai, X. Fu, T. L. Yip, H. Hu, and K. Wang, "Emission charge and liner shipping network configuration - an economic investigation of the Asia-Europe route," Transportation Research Part A: Policy and Practice, vol. 110, pp. 291-305, 2018.

[23] P. Dithmer, L. Reinhardt, and C. A. Kontovas, "The liner shipping routing and scheduling problem under environmental considerations: the case of Emissions Control Areas," in Proceedings of the International Conference on Computational Logistics, pp. 336-350, Southampton, England, October 2017.

[24] J. Xia, K. X. Li, H. Ma, and Z. Xu, “Joint planning of fleet deployment, speed optimization, and cargo allocation for liner shipping," Transportation Science, vol. 49, no. 4, pp. 922-938, 2015.

[25] China Port Association, "Compared with other regional or foreign port charges," China Ports, vol. 12, p. 14, 2017. 